Quim. Nova, Vol. 36, No. 9, 1354-1359, 2013

\title{
SODIUM DODECYL SULFATE COATED $\gamma$-ALUMINA SUPPORT MODIFIED BY A NEW SCHIFF BASE FOR SOLID PHASE EXTRACTION AND FLAME-AAS DETERMINATION OF LEAD AND COPPER IONS
}

\author{
Ardeshir Shokrollahi*, Morteza Montazerozohori and Tahere Mehrpour \\ Department of Chemistry, Yasouj University, Yasouj, 75918-74831, Iran \\ Hossein Tavallali, Batool Zare Khafri and Zohreh Montaseri \\ Department of Chemistry, Payame Noor University, Shiraz, 71365-944, Iran
}

Recebido em 21/3/13; aceito em 16/5/13; publicado na web em 25/7/13

\begin{abstract}
A simple and fast approach for solid phase extraction is herein described, and used to determine trace amounts of $\mathrm{Pb}^{2+}$ and $\mathrm{Cu}^{2+}$ metal ions. The solid phase support is sodium dodecyl sulfate (SDS)-coated $\gamma$-alumina modified with bis(2-hydroxy acetophenone)1,6-hexanediimine (BHAH) ligand. The adsorbed ions were stripped from the solid phase by $6 \mathrm{~mL}$ of $4 \mathrm{M}$ nitric acid as eluent. The eluting solution was analyzed by flame atomic absorption spectrometry (FAAS). The sorption recovery of metal ions was investigated with regard to the effects of $\mathrm{pH}$, amount of ligand, $\gamma$-alumina and surfactant and the amount and type of eluent. Complexation of BHAH with $\mathrm{Pb}^{2+}$ or $\mathrm{Cu}^{2+}$ ions was examined via spectrophotometry using the HypSpec program. The detection limit for $\mathrm{Cu}^{2+}$ was $7.9 \mu \mathrm{g} \mathrm{L}{ }^{-1}$ with a relative standard deviation of $1.67 \%$, while that for $\mathrm{Pb}^{2+}$ was $6.4 \mu \mathrm{g} \mathrm{L} \mathrm{L}^{-1}$ with a relative standard deviation of $1.64 \%$. A preconcentration factor of 100 was achieved for these ions. The method was successfully applied to determine analyte concentrations in samples of liver, parsley, cabbage, and water.
\end{abstract}

Keywords: solid phase extraction; $\mathrm{Pb}^{2+}$ and $\mathrm{Cu}^{2+}$ ions; $\mathrm{BHAH}$.

\section{INTRODUCTION}

Every day, people are exposed to a variety of chemical contaminants in food, air and manmade materials in homes and the workplace. Typically, chemical exposures are nominal, producing no recognizable health impact. But some exposures, such as high lead concentrations in aging homes, are a critical health concern especially for children. ${ }^{1}$ In recent years; a strong secular trend toward decreasing blood lead concentrations has been noted in the general population after many of the current environmental measures were adopted such as reduction in the use of leaded gasoline. ${ }^{2}$

Copper, an element essential for many biological systems, plays an important role in carbohydrate and lipid metabolism. In general, copper at nearly $40 \mu \mathrm{g} \mathrm{L}^{-1}$ is required for normal metabolism of many living organisms; however, in higher levels it is considered to be toxic and severe oral intoxication will mainly affect the blood and kidneys. ${ }^{3}$ Therefore, the ability to identify trace amounts of $\mathrm{Cu}^{2+}$ and $\mathrm{Pb}^{2+}$ ions in water is of great significance to public health and environmental safety.

The determination of trace elements in biological and environmental samples is particularly difficult because of the complex matrix and the usually low concentration of these elements in such samples, which requires sensitive instrumental techniques and frequently a preconcentration step. Although atomic absorption spectrometric methods, used either in the flame or graphite furnace mode (FAAS and ET-AAS), are a powerful analytical tool for the determination of trace elements in a great number of samples, preconcentration and separation of the metal ions with different chelating agents are still necessary for improvement of the detection limit.

Several methods have been proposed for separation and preconcentration of trace amounts of $\mathrm{Cu}^{2+}$ and $\mathrm{Pb}^{2+}$ ions. These include cloud point extraction, ${ }^{4}$ precipitation/co-precipitation. ${ }^{5}$ liquid-liquid extraction $^{6}$ and solid-phase extraction (SPE). ${ }^{7}$

In fact, solid phase extraction has become known as a powerful

*e-mail: ashokrollahi@mail.yu.ac.ir procedure for separation and enrichment of various inorganic and organic analytes.${ }^{89}$ It has several advantages over other techniques, including stability and reusability of the solid phase, reach of high preconcentration factors, easiness of separation and enrichment under dynamic conditions, no need for organic solvents and minimal costs due to low consumption of reagents. Several selective solid phase extractors have been prepared either by physical loading or chemical binding of selected chelating reagents to different solid supports such as silica gel, ${ }^{10,11}$ activated carbon, ${ }^{12,13}$ SDS-coated alumina, ${ }^{14}$ modified chromosorb, ${ }^{15}$ ion-imprinted polymers, ${ }^{16}$ Amberlite XAD-2000 resin, ${ }^{17}$ Sepabeads SP70, ${ }^{18}$ Diaion SP-850, ${ }^{19}$ nano particles ${ }^{20,21}$ and natural beds. ${ }^{22,23}$

The purpose of this work is to investigate the feasibility of using sodium dodecyl sulfate (SDS)-coated $\gamma$-alumina modified with Bis(2-hydroxy acetophenone)-1,6-hexanediimine (BHAH) as a substrate for adsorption of $\mathrm{Cu}^{2+}$ and $\mathrm{Pb}^{2+}$ ions, to determine their concentrations by flame atomic absorption spectrophotometry.

\section{EXPERIMENTAL}

\section{Instruments}

A GBC (Australia) SensAA double beam atomic absorption spectrometer equipped with deuterium background correction, and hollow cathode lamps of copper and lead as the radiation source, was used for absorbance measurements at wavelengths of 327.4 and $283.3 \mathrm{~nm}$. The acetylene flow rate and burner height were adjusted in order to obtain the maximum absorbance signal while aspirating the analyte solution. A Jenway pH meter, model 3510, was used for pH measurements. An Adam model 220 LA electronic analytical balance was used for weighing the solid materials.

\section{Reagents and solutions}

Acids and bases were of the highest purity available from Merck Company (Darmstadt, Germany) and were used as received. Doubly 
distilled deionized water was used throughout. Nitrate salts of lead, copper and the other salts were obtained from Merck Company at the highest purity available, and used without any further purification. Tetraethyl ammonium perchlorate (TEAP) was synthesized according to reference. ${ }^{24}$ Lead perchlorate was purchased from Alfa Aesar Company. The $\mathrm{pH}$ of the solutions was adjusted by adding hydrochloric acid or sodium hydroxide. For spectrophotometric studies, all solutions were prepared in acetonitrile solvent, tetrahydrofuran (THF) from Merck Company (Darmstadt, Germany).

\section{Preparation of 2 Bis(2-hydroxy acetophenone)-1,6-hexanedii- mine (BHAH)}

A solution of 2-hydroxy acetophenone $(2 \mathrm{mmol})$ in absolute ethanol $(\mathrm{EtOH})(15 \mathrm{~mL})$ was added to a solution of 1,6-hexanediimine $(1 \mathrm{mmol})$ and boiled under reflux for $4 \mathrm{~h}$. The reaction mixture was kept in the refrigerator overnight. After evaporation of the solvent, the product was obtained as a yellow crystalline powder. The crystals were filtered and washed twice with a mixture of cooled ethanol/water, and dried under air ( $85 \%$ yield). Elemental analysis, \% $\mathrm{C}_{22} \mathrm{H}_{28} \mathrm{~N}_{2} \mathrm{O}_{2}$ : Calculated: $\mathrm{C}, 74.97 ; \mathrm{H}, 8.01 ; \mathrm{N}, 7.95$; found: $\mathrm{C}, 73.9 ; \mathrm{H}, 8.2 ; \mathrm{N}, 7.7$. IR $\left(\mathrm{KBr}, \mathrm{cm}^{-1}\right): 3430$ (bs, vOH), 3057 (w, CH- Aromatic), 2922 (w, CH- aliphatic), $1613(-\mathrm{C}=\mathrm{N})$, $1572(\mathrm{C}=\mathrm{C}), 1504$ (m), 1442 (m, C=C), 1381 (m), 1373 (s, C-N), 1298 (m), 1257 (m), 1226 (m), 1157 (s), 1063 (m, C-O), 1027 (m, C-O), $913(\mathrm{~m}), 827(\mathrm{~s}), 753(\mathrm{~s}), 641(\mathrm{~m}), 503(\mathrm{~m})$. The structure of ligand is shown in Figure 1.

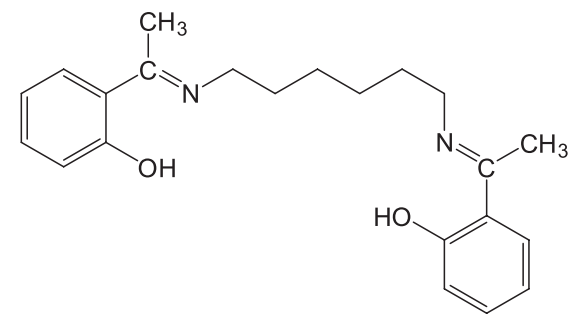

Figure 1. Structure of BHAH ligand

\section{Spectrophotometric titration}

Standard stock solutions of BHAH ligand $\left(1.0 \times 10^{-3} \mathrm{~mol} \mathrm{~L}^{-1}\right), \mathrm{Cu}^{2+}$ or $\mathrm{Pb}^{2+}$ ions $\left(1.0 \times 10^{-3} \mathrm{~mol} \mathrm{~L}^{-1}\right)$ were prepared by dissolving exactly weighted amount of $\mathrm{BHAH}$ ligand, $\mathrm{Cu}\left(\mathrm{NO}_{3}\right)_{2} \cdot 3 \mathrm{H}_{2} \mathrm{O}$ or $\mathrm{Pb}\left(\mathrm{ClO}_{4}\right)_{2}$ in pre-calibrated $25.0 \mathrm{~mL}$ volumetric flasks and diluting to the mark with acetonitrile. Working solutions were prepared by dilution of the stock solutions. Titration of a $2.6 \mathrm{~mL}$ aliquot of $\mathrm{BHAH}$ ligand solution $\left(3.8 \times 10^{-5} \mathrm{~mol} \mathrm{~L}^{-1}\right)$ was carried out at $25.0^{\circ} \mathrm{C}$ in $0.05 \mathrm{~mol}$ $\mathrm{L}^{-1}$ TEAP by using a pre-calibrated microsyringe to add solutions of $\mathrm{Cu}^{2+}$ or $\mathrm{Pb}^{2+}$ ions $\left(1.0 \times 10^{-3} \mathrm{~mol} \mathrm{~L}^{-1}\right)$. The spectra were recorded after each addition (Figure 2).

\section{Preparation of BHAH coated $\gamma$-Alumina}

About $1.0 \mathrm{~g}$ of $\gamma$-alumina was added to $50 \mathrm{mg}$ of SDS and mixed with a magnetic stirrer. After addition of $25 \mathrm{mg} \mathrm{BHAH}$ ligand dissolved in $3 \mathrm{~mL}$ THF, the $\mathrm{pH}$ was adjusted to approximately 2.5 by addition of $1 \mathrm{~mol} \mathrm{~L}^{-1} \mathrm{HCl}$. The solution was shaken for $30 \mathrm{~min}$ and filtered to prepare the solid phase. The $\mathrm{pH}$ of $250 \mathrm{~mL}$ of the solution was adjusted to 6.0 with hydrochloric acid, and passed through the solid phase column at a flow rate of $2 \mathrm{~mL} \mathrm{~min}{ }^{-1}$. The analyte was then eluted with $6 \mathrm{~mL}$ of $4 \mathrm{~mol} \mathrm{~L}^{-1}$ nitric acid. The metal ion content of the eluent was measured by FAAS. The same eluate was used to determine all analytes.

\section{Pretreatment of real samples}

Parsley and cabbage were purchased from Shiraz, Iran. A $40 \mathrm{~g}$ sample of parsley or cabbage was transferred to an oven at $120^{\circ} \mathrm{C}$ for $1 \mathrm{~h}$, then incubated in a furnace for $2 \mathrm{~h}$ at $300^{\circ} \mathrm{C}$ and for an additional $2 \mathrm{~h}$ at $500{ }^{\circ} \mathrm{C}$. The residue was cooled, and treated with $2.0 \mathrm{~mL}$ of hydrochloric acid solution $\left(2 \mathrm{~mol} \mathrm{~L}^{-1}\right)$. The filtrate, washings and volume were made up to the mark in a $500 \mathrm{~mL}$ volumetric flask and used for solid phase extraction and atomic absorption measurements. ${ }^{25}$

Water samples were analyzed as follows, to determine their analyte content. About $500 \mathrm{~mL}$ of sample was passed through a sintered glass funnel, and $1 \mathrm{~mL}$ concentrated $\mathrm{HNO}_{3}$ was added for elimination and decomposition of micro-organisms. The water samples were stored in polyethylene bottles. Then, the given procedure in general procedure section was applied for analysis.

A liver sample $(50 \mathrm{~g})$ was dried for $48 \mathrm{~h}$ in an oven at $120{ }^{\circ} \mathrm{C}$ to remove water and to obtain a constant weight (about $68 \%$ water). The dried liver sample was transferred into a glass flask. For digestion of the sample, a concentrated acid mixture of $3 \mathrm{~mL} \mathrm{H}_{2} \mathrm{SO}_{4}, 15$ $\mathrm{mL} \mathrm{HClO}_{4}$, and $15 \mathrm{~mL} \mathrm{HNO}_{3}$ was added and the sample was left to stand overnight. The solution was kept in an oil bath at $50{ }^{\circ} \mathrm{C}$ until the foaming stopped. The temperature was then increased to $150{ }^{\circ} \mathrm{C}$, and heating was continued until the brown fumes of nitrogen oxides had ceased to evolve. When a dark brown mixture was obtained, the flask was cooled for about $2 \mathrm{~min}$ prior to addition of $5 \mathrm{~mL}$ nitric acid. Heating was again continued until nitrogen oxide fumes ceased to evolve. The appearance of white fumes of perchloric acid in $1 \mathrm{~mL}$ of solution is an indication of complete digestion. ${ }^{26}$

\section{RESULTS AND DISCUSSION}

\section{Study of complexation between BHAH ligand and metal ions}

The complexation between the BHAH Schiff base and the $\mathrm{Cu}^{2+}$ or $\mathrm{Pb}^{2+}$ ions was investigated via spectrophotometry. The solutions were titrated according to spectrophotometric titration procedures, and the spectra were recorded. As shown in Figure 2a, significant changes in the ligand spectrum occurred after $\mathrm{Cu}^{2+}$ ions were added, upon which a new peak appeared at about $258-300 \mathrm{~nm}$. Addition of $\mathrm{Pb}^{2+}$ ions caused one of the original peaks of the BHAH (at about 290-340 nm) to gradually vanish, and two new peaks to appear at about $258-300 \mathrm{~nm}$ and $340-400 \mathrm{~nm}$. Their intensity increases at higher concentrations of $\mathrm{Pb}^{2+}$ ion, with very clear isobestic points, as shown in Figure 2d. These results indicate relatively strong interaction between $\mathrm{BHAH}$ and the metal ions. Analyzing the spectral data over the ranges of $260-288 \mathrm{~nm}$ and 260-280 nm yielded the stoichiometry and stability constants of the ligand with $\mathrm{Cu}^{2+}$ and $\mathrm{Pb}^{2+}$ ions, These were calculated by using the HypSpec program, a new version of the PHab program. ${ }^{27,28}$ Our group has successfully used this program for calculating the stability constants for copper complexes of a new thio Schiff base..$^{29}$

The best fits to the spectrophotometric data show that two complexes for $\mathrm{Cu}^{2+}$ ion, were obtained, these being $\mathrm{CuL}\left(\varepsilon=1.85 \times 10^{4}\right.$ mol L $\left.\mathrm{cm}^{-1}\right)$ and $\mathrm{CuL}_{2}\left(\varepsilon=5.31 \times 10^{4} \mathrm{~mol} \mathrm{~L}^{-1} \mathrm{~cm}^{-1}\right)$ whose stability constants are 5.21 and 5.01, respectively. The species obtained with the $\mathrm{Pb}^{2+}$ ion were $\mathrm{PbL}\left(\varepsilon=1.88 \times 10^{4} \mathrm{~mol} \mathrm{~L}^{-1} \mathrm{~cm}^{-1}\right)$ and $\mathrm{PbL}_{2}(\varepsilon=$ $4.96 \times 10^{4} \mathrm{~mol} \mathrm{~L}^{-1} \mathrm{~cm}^{-1}$ ) whose stability constants are 5.69 and 5.62 , respectively. The mole ratio plots and fitted curves of the respective titration spectra are depicted at $\lambda_{\max }=273 \mathrm{~nm}$ for $\mathrm{Cu}^{2+}$ (Figure 2b), and $\lambda_{\max }=270 \mathrm{~nm}$ for $\mathrm{Pb}^{2+}$ (Figure 2e). The corresponding distribution diagrams were obtained by the Hyss 2009 program, a new version of a software program that had previously been used in other reports ${ }^{30}$ (Figure $2 \mathrm{c}$, and $2 \mathrm{f}$ ). Figures $2 \mathrm{c}$ and $2 \mathrm{f}$ show that the predominant species are $\mathrm{PbL}, \mathrm{PbL}_{2}, \mathrm{CuL}$ and $\mathrm{CuL}_{2}$. 

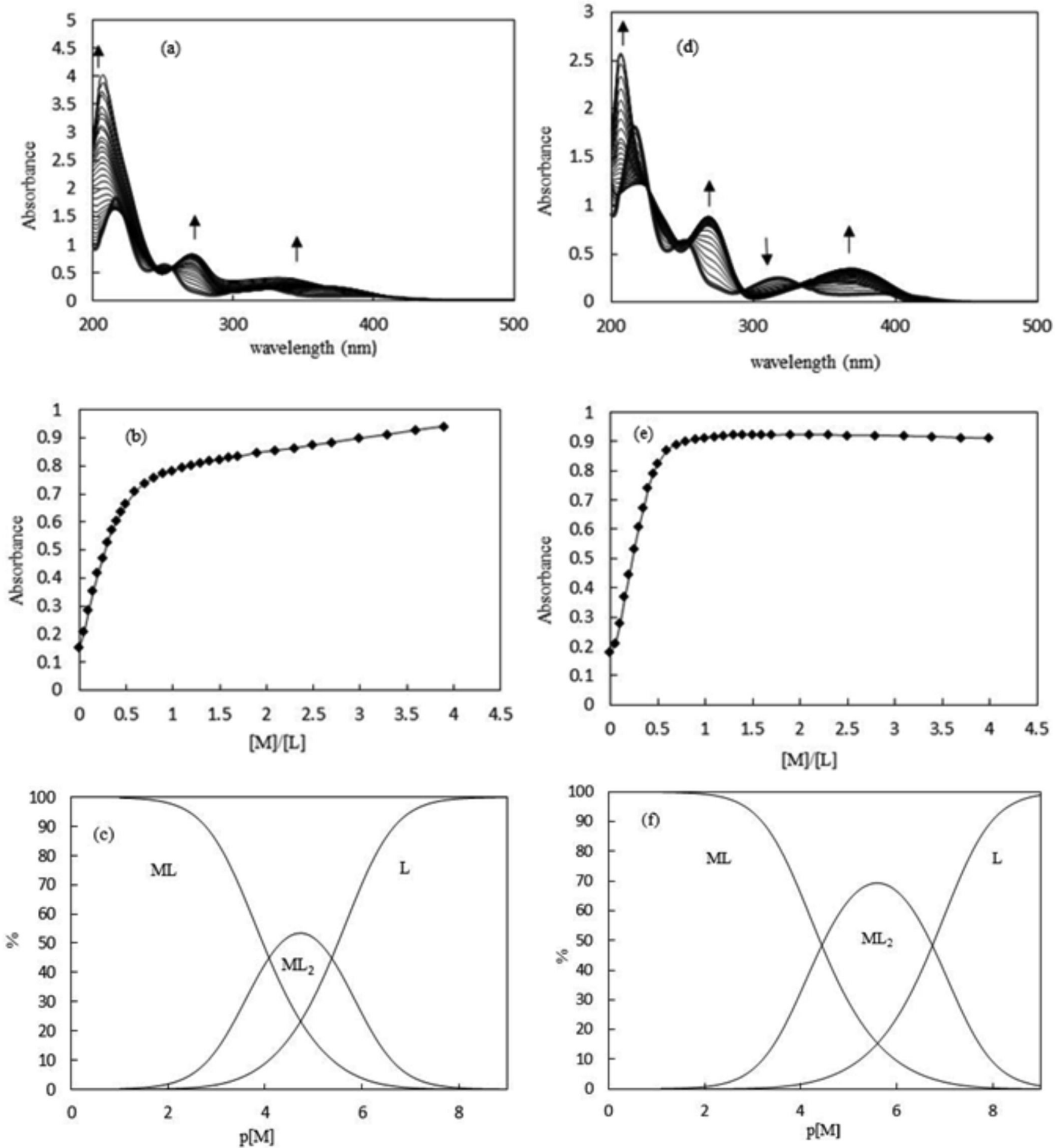

Figure 2. UV-Vis spectra for titration of $\left(3.8 \times 10^{-5} \mathrm{~mol} \mathrm{~L}^{-1}\right) \mathrm{BHAH}$ with $\left(1.0 \times 10^{-3} \mathrm{~mol} \mathrm{~L}^{-1}\right)$ metal ions. (a) $\mathrm{Cu}^{2+}$ and (d) $\mathrm{Pb}^{2+}$ ions in acetonitrile $\left(T=25^{\circ} \mathrm{C}\right.$, $I=$ $0.05 \mathrm{M}$ TEAP). ( $b, e)$ The corresponding absorption mole ratio plots at (b) $273 \mathrm{~nm}$ and (e) $270 \mathrm{~nm}$. (c, $f$ ) The corresponding distribution curves

\section{Effect of $\mathbf{p H}$}

The $\mathrm{pH}$ of the aqueous phase is one of the most important factors in solid phase extraction for quantitative recovery. This can be attributed to the fact that the metal ions are present in free cation form in an acidic medium, i.e., $\mathrm{pH} \leq 6.0$, The charge density of the functional groups of the agent, loaded on the supported solid, also plays a crucial role in the metal ion sorption.

The influence of $\mathrm{pH}$ on the adsorption of $\mathrm{Cu}^{2+}$ and $\mathrm{Pb}^{2+}$ ions onto $\gamma$-alumina modified with $\mathrm{BHAH}$ was investigated over a $\mathrm{pH}$ range of
2 to 11 , while keeping other parameters constant. Figure 3 shows that these ions were effectively adsorbed at a $\mathrm{pH}$ of 6.0 , which was selected for further experiments. The $\mathrm{pH}$ during the analytical procedure was adjusted to 6.0 by addition of $\mathrm{HCl}$ and $\mathrm{NaOH}$. The efficiency of metal ion recovery increased from $\mathrm{pH} 2.0$ to 6.0, and declined with further increases in the $\mathrm{pH}$ value. The acidity of the solution governs the dissociation of the acidic functional groups on the ligand, which provide binding sites for the metal ions. At lower $\mathrm{pH}$ values, the dissociation was suppressed greatly due to the excess $\mathrm{H}^{+}$in the sample solution, and therefore nearly no sorption took place. Higher $\mathrm{pH}$ 
facilitated the dissociation of functional groups, and thus released more binding sites for the sorption of metal ions, increasing retention efficiency. However, at $\mathrm{pH}$ higher than 6.0, the metal ions tended to cause precipitation of $\mathrm{M}(\mathrm{OH})_{\mathrm{n}}$, which resulted in heterogeneity of the fluidic flow and the contamination of the sorbent surface. Hence, a slight decline of the retention efficiency was observed at $\mathrm{pH}$ greater than 6.0. A sample $\mathrm{pH}$ value of 6.0 was consequently employed for the ensuing investigations.

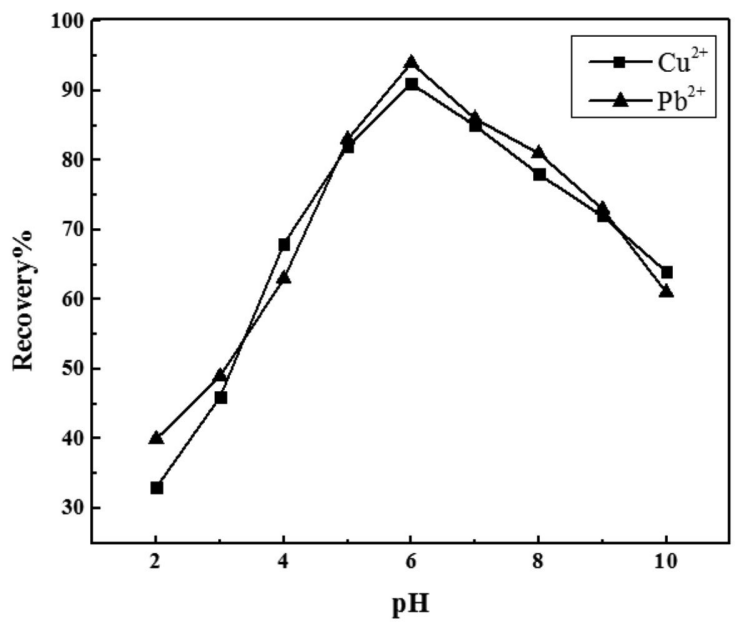

Figure 3. Effect of $\mathrm{pH}$ on recovery of metal ions. Conditions: $250 \mathrm{~mL} 0.2 \mu \mathrm{g}$ $\mathrm{mL}^{-1}$ metal ions at various $\mathrm{pH}, 1.0 \mathrm{~g} \gamma$-alumina, $50 \mathrm{mg} \mathrm{SDS}, 25 \mathrm{mg} \mathrm{BHAH}$, eluting solution $6 \mathrm{~mL}$ of $4 \mathrm{MHNO}$

\section{Effect of ligand amount}

The amount of ligand in the preconcentration studies is another main factor affecting metal ion recovery. ${ }^{31-36}$ In order to investigate the optimum amount of ligand on the quantitative extraction of these ions by the $\gamma$-alumina, the ion extraction was conducted upon varying the amount of ligand from 0 to $70 \mathrm{mg}$. The recovery of analyte ions without ligand was not quantitative. With increasing the amount of ligand up to $25 \mathrm{mg}$, an increase in recovery can be achieved. Further increase in the amount of ligand does not induce a significant change in efficiency. Quantitative recovery for the analytes was obtained using $25 \mathrm{mg}$ of BHAH. Subsequent studies for further experiments were carried out with $25 \mathrm{mg}$ of ligand (Figure 4).

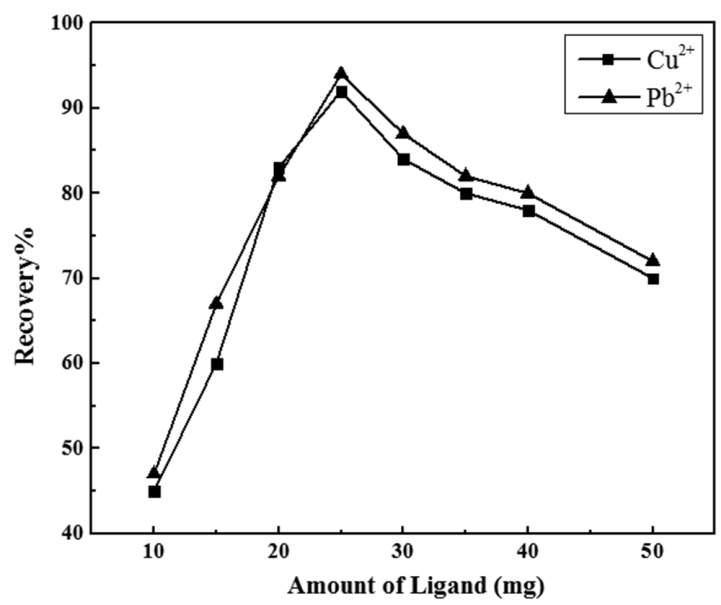

Figure 4. Effect of BHAH concentration on recovery of metal ions, Conditions: $250 \mathrm{~mL} 0.2 \mu \mathrm{g} \mathrm{mL} \mathrm{m}^{-1}$ metal ions at pH 6.0, $1.0 \mathrm{~g} \gamma$-alumina, $50 \mathrm{mg}$ SDS, different concentration of BHAH, eluting solution $6 \mathrm{~mL}$ of $4 \mathrm{M} \mathrm{HNO}_{3}$

\section{Effect of the amount of modified $\gamma$-Alumina}

In order to investigate the effect of the amount of modified $\gamma$-alumina on the quantitative extraction of $\mathrm{Cu}^{2+}$ and $\mathrm{Pb}^{2+}$ ions, the extraction was conducted with varying the amounts of the modified $\gamma$-alumina from 0.1 to $1.5 \mathrm{mg}$. Quantitative recovery ( $>92 \%$ ) of $\mathrm{Cu}^{2+}$ and $\mathrm{Pb}^{2+}$ ions was obtained with increasing the amount of modified $\gamma$-alumina up to $1.0 \mathrm{mg}$. Hence, $1.0 \mathrm{mg}$ of the modified $\gamma$-alumina was used for further experiments, due to the greater availability of the surface area at high amounts of the sorbent, and to account for other extractable species.

\section{Effect of amount of SDS on metal ion recovery}

The influence of SDS amount on the percentage of complexed ions that were ad-solubilized was investigated by passing $250 \mathrm{~mL}$ of a solution containing $0.2 \mu \mathrm{g} \mathrm{mL} \mathrm{L}^{-1}$ of each metal ion through a solid phase comprising various amounts of SDS, $1.0 \mathrm{~g} \gamma$-alumina and 25 mg BHAH at $\mathrm{pH} 6$. The presence of surfactant favors the formation of hydrophobic complexes. Figure 5 shows that the recovery of metal ions increased at higher amounts of SDS, up to $50 \mathrm{mg}$, because of the formation of hydrophobic ternary ion pairs (M-ligand-SDS) that increase the retention of ternary ion pairs on the modified solid phase. The retention of metal ions on hemimicelles, which have a hydrophobic surface, was clearly dependent on the polarity of the analyte complex. The formation of minute amounts of admicelles was essential to achieve complete adsolubilization of the chelates of these ions. At surfactant amounts higher than about $50 \mathrm{mg}$, a gradual decrease in the retention percentage of ions was observed, due to the formation of micelles in the bulk aqueous solution or due to complexation of SDS with ligand to form an ion pair with metal ions. As a result, it was more difficult for the SDS-coated solid phase to desorb BHAH into aqueous solution.

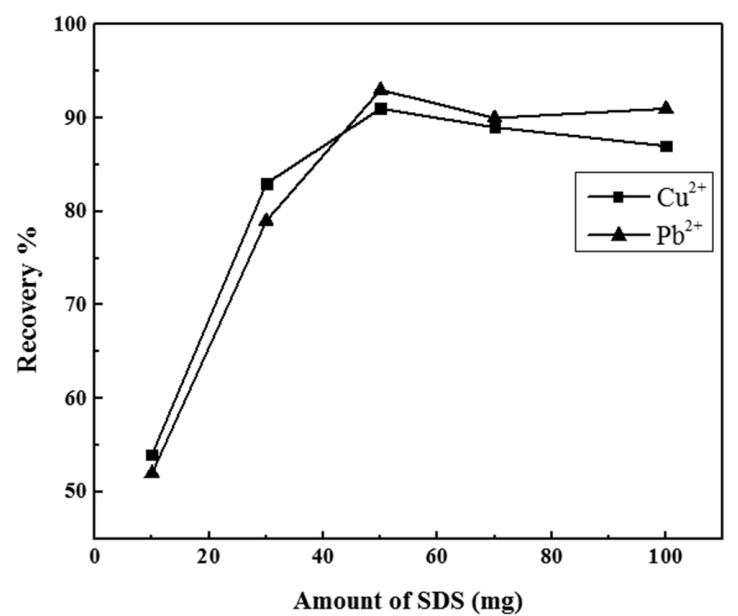

Figure 5. Effect of SDS on recovery of metal ions, Conditions: $250 \mathrm{~mL} 0.2$ $\mu \mathrm{g} \mathrm{mL} L^{-1}$ metal ions at $\mathrm{pH}$ 6.0, $1.0 \mathrm{~g} \gamma$-alumina, $25 \mathrm{mg}$ BHAH, eluting solution $6 \mathrm{~mL}$ of $4 \mathrm{M} \mathrm{HNO}_{3}$

\section{Selection of eluent and optimization of eluent concentration}

To select the best eluent, the effect of various acidic solutions such as sulfuric, perchloric, hydrochloric, and phosphoric acid on the preconcentration yields of the metal ions was studied under optimum conditions. Higher recovery efficiency was observed with nitric acid, which was therefore selected as the proper eluent. Experiments were carried out to select the concentration of nitric acid solution. Concentrations of $\mathrm{HNO}_{3}$ solutions between 1.0 to $6.0 \mathrm{~mol} \mathrm{~L}^{-1}$ were 
Table 1. Comparative data for preconcentration of analytes ions by SPE procedure using chemically modified sorbents

\begin{tabular}{|c|c|c|c|c|c|c|}
\hline Metal ions & Sorbent & $\begin{array}{l}\text { Determinaton } \\
\text { method }\end{array}$ & $\begin{array}{l}\text { Sample volume } \\
(\mathrm{mL})\end{array}$ & $\begin{array}{l}\text { Preconcentration or enri- } \\
\text { chment factor }\end{array}$ & $\begin{array}{l}\text { LOD } \\
\left(\mu \mathrm{g} \mathrm{L}^{-1}\right)\end{array}$ & References \\
\hline $\begin{array}{c}\mathrm{Cd}^{2+}, \mathrm{Co}^{2+}, \mathrm{Cu}^{2+}, \\
\mathrm{Cr}^{3+} \mathrm{Pb}^{2+}, \mathrm{Zn}^{2+}\end{array}$ & $\begin{array}{l}\text { sodium dodecyl sulfate (SDS)- } \\
\text { coated poly vinyl chloride (PVC) } \\
\text { modified with (BHABDI) ligand }\end{array}$ & FAAS & 200 & 50 & $1.2-3.1$ & 37 \\
\hline $\mathrm{Fe}^{3+}, \mathrm{Cu}^{2+}, \mathrm{Zn}^{2+}$ & $\begin{array}{c}\text { (PHBI) loaded on Triton X- } \\
\text { 100-coated polyvinyl chloride } \\
\text { (PVC). }\end{array}$ & FAAS & 450 & 90 & $0.95-1.00$ & 38 \\
\hline $\mathrm{Cu}^{2+}, \mathrm{Cr}^{3+}, \mathrm{Pb}^{2+}$ & $\begin{array}{l}\text { Bismuthiol-II-immobilized mag- } \\
\text { netic nanoparticles }\end{array}$ & ICP-OES & 100 & $95,96,87$ & $0.058,0.043,0.085$ & 39 \\
\hline $\begin{array}{l}\mathrm{Cu}^{2+}, \mathrm{Ni}^{2+}, \mathrm{Co}^{2+}, \\
\mathrm{Pb}^{2+}\end{array}$ & $\begin{array}{l}\text { (DHMP) loaded on activated } \\
\text { carbon }\end{array}$ & FAAS & 1300 & 260 & $2.9,3.5,8.4,3.4$ & 26 \\
\hline $\mathrm{Cu}^{2+}, \mathrm{Pb}^{2+}$ & $\begin{array}{c}\text { (SDS)-coated } \gamma \text {-alumina } \\
\text { modified with Bis(2-hydroxy } \\
\text { acetophenone)-1,6-hexanediimine } \\
\text { (BHAH) ligand }\end{array}$ & FAAS & 1000 & 100 & $7.9,6.4$ & This work \\
\hline
\end{tabular}

studied for this purpose. The recovery values increased upon adding nitric acid. Quantitative recovery of the analytes was observed after adding $4.0 \mathrm{~mol} \mathrm{~L}^{-1} \mathrm{HNO}_{3}$; at higher concentration it is possible that the ligand and analytes were eluted together, and this may reduce the atomization efficiency. The optimum nitric acid concentration and volume were determined to be $4 \mathrm{~mol} \mathrm{~L}^{-1}$ and $6 \mathrm{~mL}$, respectively.

\section{Effect of sample flow rate and volume}

The retention of analytes on the sorbent depends on the flow rate of the solution. The influence of metal ion sorption on modified $\gamma$-alumina was investigated by varying the flow rate of the sample solution in the range of $1-6 \mathrm{~mL} \mathrm{~min}^{-1}$, and by passing the solution through the solid phase column. The recovery of the analytes decreased when the flow rate was greater than $2.0 \mathrm{~mL} \mathrm{~min}^{-1}$. Hence, a flow rate of $2.0 \mathrm{~mL} \mathrm{~min}^{-1}$ was employed in this work.

Sample volume is an important parameter for obtaining high preconcentration. To select the optimal sample volume, the volume of sample solution, containing $0.2 \mu \mathrm{g} \mathrm{mL}^{-1}$ of $\mathrm{Pb}^{2+}$ or and $\mathrm{Cu}^{2+}$ ions, was varied from 100 to $2000 \mathrm{~mL}$. The metal ions were preconcentrated on the modified $\gamma$-alumina. The effect of sample volume on the preconcentration and extraction efficiency was tested in the range of 100-2000 mL. Quantitative recovery ( > 92\%) of $\mathrm{Pb}^{2+}$ and $\mathrm{Cu}^{2+}$ ions was obtained for up to $1000 \mathrm{~mL}$ of sample solution. The preconcentration factor was 100 for sample solutions, because the final elution volume was diluted to $10 \mathrm{~mL}$. The dilution of the solution with increasing volume, for a constant amount of analyte, caused the recovery of sorption to decrease.

\section{Analytical performance}

The figures of merit of the proposed method were investigated under the optimum conditions determined as above. The dynamic linear range for $\mathrm{Cu}^{2+}$ and $\mathrm{Pb}^{2+}$ ions was calculated in the concentration range of $0.01-0.40 \mu \mathrm{g} \mathrm{mL}^{-1}$ from the equations $A=0.524 C+0.039$ for $\mathrm{Cu}^{2+}$ and $A=0.393 C+0.032$ for $\mathrm{Pb}^{2+}$. The detection limit (DL) is obtained from $3 S_{b} / m$, where $S_{b}$ is the standard deviation of five replicate blank measurements, and $m$ is the slope of calibration curve. The DL of the proposed method was $7.9 \mu \mathrm{g} \mathrm{L}^{-1}$ for $\mathrm{Cu}^{2+}$ and $6.4 \mu \mathrm{g} \mathrm{L}^{-1}$ for $\mathrm{Pb}^{2+}$ ions under the optimum conditions. The proposed method exhibited good reproducibility, with a relative standard deviation (RSD) of $1.67 \%$ for $\mathrm{Cu}^{2+}$ and $1.64 \%$ for $\mathrm{Pb}^{2+}$ (five replicate measurements at $0.2 \mu \mathrm{g} \mathrm{mL} \mathrm{m}^{-1}$ metalions). The theoretical preconcentration factor, calculated as the ratio of the initial sample volume $(1000 \mathrm{~mL})$ to the final volume after preconcentration $(10.0 \mathrm{~mL})$, was 100 .

According to the figures of merit of the proposed method in comparison with other reported solid phase extraction methods, ${ }^{26,37-39}$ the proposed method showed very good sensitivity and precision for determining $\mathrm{Cu}^{2+}$ and $\mathrm{Pb}^{2+}$ ions. The results are summarized in Table 1 .

\section{Effect of contaminant ions}

In the determination of metal ions by atomic absorption spectrophotomety, the level of foreign ions is an important problem. In order to assess the possible analytical applications of the proposed procedure for preconcentration, the effect of foreign ions was examined under the optimized conditions. Trace amounts of foreign ions can interfere with the determination of analyte ions in various real medium samples. The results are shown in Table 2. The tolerable limit was defined as the highest amount of foreign ions that produced an error not exceeding $5 \%$ by a combination of solid phase column extraction and atomic absorption spectrometry. The experiments summarized in Table 2 indicated that within $\pm 5 \%$ error range, interference from most of inorganic cations and some anions was not observed. No tests were conducted at higher concentration levels. For real samples, the content of the afore mentioned coexisting species is usually lower than the tolerated concentration levels, therefore, the present protocol can be readily exploited directly and no further sample treatments or masking reagents are needed.

Table 2. Effects of the interferences ions on the recoveries of the examined metal ions

\begin{tabular}{lccc}
\hline \multirow{2}{*}{ Ion } & \multirow{2}{*}{$\begin{array}{c}\text { Interference/analyte } \\
\text { ratio }(\mathrm{w} / \mathrm{w})\end{array}$} & \multicolumn{2}{c}{ Recovery $(\%)$} \\
\cline { 3 - 4 } Without interference ion & --- & 93 & $\mathrm{Cu}^{2+}$ \\
$\mathrm{K}^{+}, \mathrm{Na}^{+}, \mathrm{Li}^{+}$ & 1000 & 95 & 93 \\
$\mathrm{SCN}^{-}, \mathrm{HCO}_{3}^{-}$ & 1000 & 95 & 93 \\
$\mathrm{Ba}^{2+}, \mathrm{Mg}^{2+}$ & 600 & 93 & 94 \\
$\mathrm{Co}^{2+}, \mathrm{Cd}^{2+}, \mathrm{Ni}^{2+}$ & 500 & 91 & 92 \\
$\mathrm{Hg}^{2+}$ & 200 & 94 & 91 \\
$\mathrm{Cr}^{3+}$ & 200 & 91 & 93 \\
$\mathrm{Fe}^{3+}$ & 150 & 92 & 93 \\
\hline
\end{tabular}




\section{Application of method to analyze real samples}

In order to assess how well the method may be applied to real samples, which often have complex matrices containing varying amounts of diverse ions, the method was applied to the separation and recovery of analytes from liver, parsley, cabbage, and water. The reliability was verified by performing spiking experiments, using the standard addition method. The percent recovery for each element in spiked real samples is given in Tables 3 and 4 . The results of three analyses of each sample show that, in all cases, the ions recoveries is almost quantitative with a low relative standard deviation.

Table 3. Analysis of analyte ions in water samples $(\mathrm{N}=3)$

\begin{tabular}{llcccc}
\hline Analyte & Sample & $\begin{array}{c}\text { Added } \\
\left(\mu \mathrm{g} \mathrm{mL}^{-1}\right)\end{array}$ & $\begin{array}{c}\text { Found } \\
\left(\mu \mathrm{g} \mathrm{mL}^{-1}\right)\end{array}$ & $\begin{array}{c}\text { Recovery } \\
(\%) \pm \mathrm{SD}^{\mathrm{b}}\end{array}$ & $\begin{array}{c}\mathrm{RSD}^{\mathrm{c}} \\
(\%)\end{array}$ \\
\hline $\mathrm{Cu}^{2+}$ & Spring water & 0.00 & 0.65 & --- & \\
& & 0.50 & 1.14 & $98.0 \pm 0.7$ & 0.71 \\
& Tap water & 0.00 & 0.62 & --- & \\
& & 0.50 & 1.13 & $102.2 \pm 0.9$ & 0.88 \\
\hline $\mathrm{Pb}^{2+}$ & Spring water & 0.00 & 0.07 & --- & \\
& & 0.50 & 0.53 & $92.0 \pm 0.8$ & 0.87 \\
& Tap water & 0.00 & $\mathrm{Nd}^{\mathrm{a}}$ & --- & \\
& & 0.50 & 0.46 & $92.0 \pm 0.6$ & 0.65 \\
\hline
\end{tabular}

a)Not detected. b) Standard deviation. c) Relative standard deviation.

Table 4. Analysis of analyte ions in meat and vegetable samples $(\mathrm{N}=3)$

\begin{tabular}{llcccc}
\hline Analyte & Sample & $\begin{array}{c}\text { Added } \\
(\mu \mathrm{g} / \mathrm{g})\end{array}$ & $\begin{array}{c}\text { Found } \\
(\mu \mathrm{g} / \mathrm{g})\end{array}$ & $\begin{array}{c}\text { Recovery } \\
(\%) \pm \mathrm{SD}^{\mathrm{b}}\end{array}$ & $\begin{array}{c}\mathrm{RSD}^{\mathrm{c}} \\
(\%)\end{array}$ \\
\hline $\mathrm{Cu}^{2+}$ & Liver & 0.00 & 0.58 & --- & \\
& & 6.25 & 6.83 & $100.0 \pm 0.9$ & 0.90 \\
& Parsley & 0.00 & 1.00 & --- & \\
& & 6.25 & 7.06 & $97.00 \pm 0.9$ & 0.93 \\
& Cabbage & 0.00 & 1.37 & --- & \\
& & 6.25 & 7.56 & $99.0 \pm .9$ & 0.91 \\
\hline $\mathrm{Pb}^{2+}$ & Liver & 0.00 & $\mathrm{Nd}^{\mathrm{a}}$ & --- & \\
& & 6.25 & 6.13 & $98.0 \pm 0.7$ & 0.71 \\
& Parsley & 0.00 & $\mathrm{Nd}$ & --- & \\
& & 6.25 & 6.38 & $102.0 \pm 0.8$ & 0.78 \\
& Cabbage & 0.00 & $\mathrm{Nd}$ & -- & \\
& & 6.25 & 6.25 & $100.0 \pm 0.9$ & 0.90 \\
\hline
\end{tabular}

a) Not detected b) Standard deviation c) Relative standard deviation.

\section{CONCLUSION}

The present study describes a new solid phase extraction procedure for environmental samples. The method involves the preconcentration of $\mathrm{Cu}^{2+}$ or $\mathrm{Pb}^{2+}$ ions on SDS-coated $\gamma$-alumina modified with $\mathrm{BHAH}$ ligand, followed by spectrophotometric measurement of the complexation, and finally determination of analyte ions by FAAS. The procedure provides a simple, rapid, economic, selective and reproducible method for the separation, preconcentration and determination of metal ions. The system successfully preconcentrated analyte ions in low amounts from large sample volumes $(1000 \mathrm{~mL})$. The proposed preconcentration/separation method can also be applied to determine analyte ions in real samples with complex matrices.

\section{REFERENCES}

1. Wilhelm, M.; Pesch, A.; Rostek, U.; Begerow, J.; Schmitz, N.; Idel, H.; Ranft, U.; Sci. Total Environ. 2002, 297, 109.

2. Vupputuri, S.; He, J.; Muntner, P.; Bazzano, L. A.; Whelton, P. K.; Ba- tuman, V.; Hypertension 2003, 41, 463.

3. Tabrizi, H. B.; J. Hazard. Mater. 2007, B139, 260.

4. Tang, A. N.; Jiang, D. Q.; Yan, X. P.; Anal. Chim. Acta 2004, 507, 203.

5. Atanassova, D.; Stefanova, V.; Russeva, E.; Talanta 1998, 47, 1237.

6. EI-Hussaini, O. M.; Rice, N. M.; Hydrometallurgy 2004, 72, 259.

7. Meng, F. Y.; Wei, Y. Q.; Lu, H.; Liu, X. X.; Liu, J. X.; Chin. Chem. Lett. 2012, 23, 591 .

8. Bezerra, M. A.; dos Santos, W. N. L.; Lemos, V. A.; Korn, M. G. A.; Ferreira, S. L. C.; J. Hazard. Mater. 2007, 148, 334.

9. Adhikari, B. B.; Gurung, M.; Kawakita, H.; Ohto, K.; Chem. Eng. Sci. 2012, 78, 144

10. Gentscheva, G.; Tzvetkova, P.; Vassileva, P.; Lakov, L.; Peshev, O.; Ivanova, E.; Microchim. Acta 2006, 156, 303.

11. Akhond, M.; Absalan, G.; Sheikhian, L.; Eskandari, M. M.; Sharghi, H.; Sep. Purif. Technol. 2006, 52, 53.

12. Zhang, L.; Chang, X.; Li, Zh.; He, Q.; J. Mol. Struct. 2010, 964, 58.

13. Zhao, Y.; Liu, Ch.; Feng, M.; Chen, Zh.; Li, Sh.; Tian, G.; Wang, L.; Huang, J.; Li, Sh.; J. Hazard. Mater. 2010, 176, 119.

14. Mohammadi, S. Z.; Hamidian, H.; Karimzadeh, L.; Moeinadini, Z.; Arabian J. Chem. 2012, In press.

15. Ghaedi, M.; Fathi, M. R.; Shokrollahi, A.; Shajarat, F.; Anal. Lett. 2006, 39, 1171.

16. Rao, T. P.; Daniel, S.; Gladis, J. M.; TrAC, Trends Anal. Chem. 2004, 23, 28.

17. Duran, C.; Senturk, H. B.; Gundogdu, A.; Bulut, V. N.; Elci, L.; Soylak, M.; Tufekci, M.; Uygur, Y.; Chin. J. Chem. 2007, 25, 196.

18. Ghaedi, M.; Shabani, R.; Montazerozohori, M.; Shokrollahi, A.; Sahraiean, A.; Hossainian, H.; Soylak, M.; Environ. Monit. Assess. 2011, 174, 86.

19. Shokrollahi, A.; Ghaedi, M.; Shabani, R.; Montazerozohori, M.; Chehreh, F.; Soylak, M.; Alipour, S.; Food Chem. Toxicol. 2010, 48, 482.

20. Ghaedi, M.; Tavallali, H.; Shokrollahi, A.; Zahedi, M.; Montazerozohori, M.; Soylak, M.; J. Hazard. Mater. 2009, 166, 1441.

21. Yin, J.; Jiang, Z. C.; Chang, G.; Hu, B.; Anal. Chim. Acta 2005, 540, 333.

22. Chen, M. L.; Tian, Y.; Wang, J. H.; J. Anal. At. Spectrom. 2008, 23, 876.

23. Faraji, M.; Yamini, Y.; Shariati, S.; J. Hazard. Mater. 2009, 166, 1383.

24. Kolthoff, I. M.; J. Am. Chem. Soc. 1957, 79, 1.

25. Horwitz W.; Official methods of analysis of AOAC International, Gaithersburg, MD, 2002.

26. Ghaedi, M.; Ahmadi, F.; Shokrollahi, A.; J. Hazard. Mater. 2007, 142, 272.

27. Gans, P.; Sabatini, A.; Vacca, A.; Talanta 1996, 43, 1739.

28. Gans, P.; Sabatini, A.; Vacca, A.; Ann. Chim. 1999, 89, 45.

29. Shokrollahi, A.; Abbaspour, A.; Ghaedi, M.; Naghashian Haghighi, A.; Kianfar, A. H.; Ranjbar, M.; Talanta 2011, 84, 34.

30. Alderighi, L.; Gans, P.; Ienco, A.; Peters, D.; Sabatini, A.; Vacca, A.; Coord. Chem. Rev. 1999, 184, 311.

31. Soylak, M.; Tuzen, M.; J. Hazard. Mater. 2006, 138, 195.

32. Soylak, M.; Karatepe A. U.; Elci, L.; Dogan, M.; Turk. J. Chem. 2003, 27, 235.

33. Shahtaheri, S. J.; Khadem, M.; Golbabaei, F.; Rahimi-Froushan, A.; Ganjali, M. R.; Norozi, P.; Iran. J. Public Health 2007, 36, 73.

34. Mahmoud, M. E.; Osman, M. M.; Amer, M. E.; Anal. Chim. Acta 2000, $15,433$.

35. Suvardhan, K.; Kumar, K. S.; Rekha, D.; Kiran, K.; Raj B. J.; Chiranjeevi, P.; J. Anal. Chem. 2007, 62, 336.

36. Suleiman, J. S.; Hu, B.; Pu, X.; Huang, C.; Jiang, Z.; Microchim. Acta 2007, 159, 379.

37. Marahel, F.; Ghaedi, M.; Shokrollahi, A.; Montazerozohori, M.; Davoodi, Sh.; Chemosphere 2009, 74, 583.

38. Ghaedi, M.; Niknam, Kh.; Shokrollahi, A.; Niknam, E.; Ghaedi, H.; Soylak, M.; J. Hazard. Mater. 2008, 158, 131.

39. Suleiman, J. S.; Hu, B.; Peng, H.; Huang, Ch.; Talanta 2009, 77, 1579. 